\title{
Faktor-faktor yang Memengaruhi Gambaran Elektroensefalografi Interiktal Anak Epilepsi
}

Yanuar Nusca Permana, Alifiani Hikmah Putranti, Henry Setiawan

Departemen Ilmu Kesehatan Anak Fakultas Kedokteran Universitas Diponegoro/RSUP Dr. Kariadi, Semarang

Latar belakang. Elektroensefalografi (EEG) sebagai pemeriksaan penunjang sangat penting dalam mendiagnosis epilepsi bila didukung dengan data klinis. Hasil perekaman EEG dipengaruhi banyak faktor dan sekitar 50\% epilepsi pada anak sering tidak menunjukkan aktivitas gelombang epileptiform. Dengan mengetahui faktor-faktor yang memengaruhi EEG, upaya awal untuk diagnosis dan tata laksana epilepsi pada anak dapat lebih efektif dan efisien.

Tujuan. Untuk menganalisis faktor-faktor yang memengaruhi gambaran EEG interiktal pada anak epilepsi.

Metode. Penelitian ini merupakan penelitian cross sectional pada anak epilepsi usia antara 1-18 tahun, yang melakukan pemeriksaan EEG selama Januari 2013 - Mei 2016 di CDC RSUP dr. Kariadi Semarang. Data dikumpulkan dengan wawancara terstruktur dan observasi langsung meliputi usia, jenis kelamin, jenis epilepsi, episode terakhir bangkitan epilepsi, dan penggunaan obat anti-epilepsi. Data dianalisis dengan chi square dan regresi logistik.

Hasil. Hasil yang diperoleh bahwa variabel yang memengaruhi gambaran EEG interiktal adalah episode terakhir dari bangkitan epilepsi (OR=3,4; 95\%CI 1,286-9,334) dan penggunaan obat anti-epilepsi (OR=52,8; 95\%CI 15.962-174.795).

Kesimpulan. Faktor-faktor yang memengaruhi gambaran EEG interiktal pada anak epilepsi adalah episode terakhir dari bangkitan epilepsi dan penggunaan obat anti-epilepsi. Sari Pediatri 2020;22(1):13-7

Kata kunci: EEG, obat anti-epilepsi, episode terakhir bangkitan epilepsi

\section{Factors Affecting Interictal Electroencephalographic Features of Children with Epilepsy}

Yanuar Nusca Permana, Alifiani Hikmah Putranti, Henry Setiawan

Background. Electroencephalographic (EEG) which is supported by clinical data is an important additional facility in diagnosing epilepsy. The EEG recording result affected by many factors and approximately $50 \%$ epilepsy cases in children often showing nonepileptic-form wave activity. By knowing the factors that affecting EEG, initial attempt for diagnosis and management of epilepsy in children can become more effective and efficient

Objectives. To analyze factors that affecting interictal electroecephalography imaging in children with epilepsy

Methods. This was a cross sectional study of children with epilepsy age 1-18 years, between January 2013 and May 2016 in CDC RSUP dr. Kariadi Semarang and had EEG performed. Data collected by structured interview and direct observational including age, gender, type of epilepsy, last episode of an epileptic seizure, and the use of anti-epileptic drugs. Data were analyzed by chi square and logistic regression

Result. Variables found affecting interictal electroencephalography results in children with epilepsy are last episode of epileptic seizure $(\mathrm{OR}=3,4 ; 95 \% \mathrm{CI} 1,286-9,334)$ and the use of anti-epileptic drugs $(\mathrm{OR}=52,8 ; 95 \% \mathrm{CI} 15,962-174,795)$ Conclusion. Factors that affecting inter iktal electroencephalography imaging in children with epilepsy is last episode of epileptic seizure and the use of anti-epileptic drugs. Sari Pediatri 2020;22(1):13-7

Keywords: EEG, anti-epileptic drugs, last episode of epileptic seizure

Alamat korespondensi: Yanuar Nusca Permana. Departemen Ilmu Kesehatan Anak Fakultas Kedokteran Universitas Diponegoro / RSUP Dr. Kariadi, Semarang Indonesia. Email: nusca_permana@ymail.com 
Yanuar Nusca Permana dkk: Faktor-faktor yang memengaruhi gambaran elektroensefalografi interiktal anak epilepsi

$\mathrm{E}$ pilepsi adalah suatu keadaan yang ditandai kejang berulang (dua kali atau lebih) tanpa diprovokasi oleh penyebab jelas. ${ }^{1}$ Epilepsi merupakan suatu kelainan neurologis kronik paling banyak ditemukan pada masa anakanak. Insiden kejang tanpa provokasi dan epilepsi sekitar 20-80 per 100.000 anak pertahun. Tujuh puluh persen penyandang epilepsi terjadi pada dua dekade pertama kehidupan, dimana Kejang berulang dan status epilepsi di masa anak sangat umum terjadi. ${ }^{2}$ Terdapat paling sedikit 700.000-1.400.000 kasus epilepsi di Indonesia dengan pertambahan sebesar 70.000 kasus baru setiap tahun dan diperkirakan 40\%-50\% terjadi pada anak. ${ }^{3}$

Banyak kejadian non epilepsi menyerupai kejang, seperti misalnya sinkop kardiogenik atau sinkop vasovagal, sinkop neurogenik, transient ischemic attack, gangguan tidur, serangan panik atau suatu gambaran perilaku. ${ }^{2}$ Sebanyak $20-30 \%$ pasien yang dirujuk ke klinik epilepsi ternyata bukan penderita epilepsi, yaitu $44 \%$ di antaranya menderita sinkop, 20\% kelainan psikiatrik, $11 \%$ serangan menahan nafas (breath holding spell), $6 \%$ migren, $6 \%$ night terror, dan $11 \%$ lain-lainnya. ${ }^{4}$

Epilepsi adalah diagnosis klinis yang tidak hanya dapat dibuat berdasarkan hasil EEG yang abnormal. Faktanya, EEG abnormal dapat ditemukan pada $5 \%$ anak-anak yang tidak memiliki riwayat kejang. ${ }^{5}$ Meskipun diagnosis epilepsi lebih didasarkan atas gambaran klinis saat terjadi bangkitan, namun temuan pemeriksaan EEG dengan interpretasi yang didukung data klinis sering dapat membantu diagnosis.

Sebagai penunjang diagnosis, EEG membantu dalam mendiagnosis kejang dan berbagai sindrom epilepsi anak yang memiliki implikasi terapi yang signifikan. EEG memiliki peran dalam penghentian terapi dan monitoring obat. Akan tetapi, EEG juga memiliki keterbatasan tersendiri yaitu dapat memberikan gambaran normal pada anak epilepsi dan gambaran abnormal pada yang normal. Gambaran EEG normal dapat dijumpai hampir 50\% pada anak dengan epilepsi. ${ }^{6}$

Atas dasar itulah perlu dilakukan penelitian tentang faktor-faktor yang mempengaruhi gambaran EEG inter iktal anak yang menderita epilepsi sebagai salah satu upaya awal mendiagnosis dan mengelola epilepsi pada anak secara lebih efektif dan efisien.

\section{Metode}

Penelitian ini merupakan penelitian belah lintang (cross sectional). Data diambil dari setiap pasien baru dengan diagnosis epilepsi di poliklinik anak dan ruang rawat inap anak di RSUP Dr. Kariadi Semarang. Setelah orang tua pasien mendapatkan penjelasan tentang penelitian dan menandatangani informed consent, dilakukan pengumpulan data dengan wawancara langsung dan kuesioner yang ditanyakan pemeriksa kepada orangtua meliputi usia, jenis kelamin, jenis epilepsi, bangkitan epilepsi terakhir, obat anti epilepsi. Kriteria inklusi adalah semua pasien epilepsi yang baru didiagnosis secara klinis, berusia 1-18 tahun kemudian melakukan pemeriksaan EEG. Sementara kriteria eksklusi adalah gambaran EEG yang sulit diintrepretasikan, anak dengan mikrosefali, paska operasi otak, keterlambatan perkembangan serta jika pasien atau orangtua menolak turut dalam penelitian. Hasil perekaman EEG diperiksa oleh konsultan neurolog. Data yang terkumpul diolah komputer dan disajikan dalam tabel dan narasi. Data dianalisis dengan chi-square dan regresi logistik. Penelitian telah mendapatkan laik etik dari Komisi Etik FK UNDIP/ RSUP dr. Kariadi Semarang.

\section{Hasil}

Selama penelitian Januari 2014-Mei 2016 didapatkan 141 responden berpartisipasi pada penelitian ini. Kasus terbanyak 52,5\% terjadi pada anak laki-laki. Pada pemeriksaan didapatkan sebanyak $71,6 \%$ pasien mengalami epilepsi umum, 28,4\% epilepsi parsial, $63.8 \%$ pasien menggunakan obat epilepsi sebelum EEG, dengan bangkitan epilepsi terakhir sebelum pemeriksaan EEG >24 jam 51,1\%. Hasil Perekaman EEG 54,6\% didapatkan normal (Tabel 1).

Sebagian besar kasus dengan bangkitan epilepsi $>24$ jam $(68,1 \%)$ memberikan hasil EEG normal, sedangkan 40,6\% kasus dengan bangkitan epilepsi $\leq 24$ jam memberikan hasil EEG normal. Pasien yang mengalami bangkitan epilepsi terakhir $<24$ jam memberikan hasil EEG abnormal sebanyak 59,4\% dibandingkan pasien yang mengalami bangkitan epilepsi terakhir $>24$ jam hanya sebesar 31,9\%. Subyek yang menggunakan obat anti epilepsi sebelum pemeriksaan EEG memberikan hasil EEG abnormal sebesar $18,9 \%$, sedangkan yang tidak menggunakan 
Tabel 1. Karakteristik subyek penelitian

\begin{tabular}{lcc}
\hline & & $\mathrm{n}(\%)$ \\
\hline Jenis kelamin & Laki-laki & $74(52,5)$ \\
Tingkat pendidikan penderita & Perempuan & $67(47,5)$ \\
& Belum sekolah & $52(36,9)$ \\
& TK & $14(9,9)$ \\
& SD & $48(34)$ \\
& SLTP & $20(14,2)$ \\
& SLTA & $6(4,3)$ \\
Tingkat pendidikan ayah & Lainnya & $1(0,7)$ \\
& Tidak sekolah & $2(1,4)$ \\
& SD & $11(7,8)$ \\
& SLTP & $23(16,3)$ \\
Tingkat pendidikan ibu & SLTA & $82(58,2)$ \\
& Akademi & $11(7,8)$ \\
& Perguruan tinggi & $12(8,5)$ \\
& Tidak sekolah & $2(1,4)$ \\
Jenis epilepsi & SD & $14(9,9)$ \\
Bangkitan epilepsi terakhir sebelum pemeriksaan EEG & SLTP & $36(25,5)$ \\
Hasil EEG & SLTA jam & $71(50,4)$ \\
& Akademi & $6(4,3)$ \\
Sumber anamnesis & Perguruan tinggi & $11(7,8)$ \\
& Lainnya & $1(0,7)$ \\
& Normal & $102(72,3)$ \\
& Abnormal & $2(1,4)$ \\
& & $2(1,4)$ \\
& Ayah kandung & $90(63,8)$ \\
& Lainnya & $51(36,2)$ \\
& Ya & $101(71,6)$ \\
& Tidak & $40(28,4)$ \\
& Umum & $69(48,9)$ \\
& Parsial & $72(51,1)$ \\
& $77(54,6)$ \\
& $64(45,4)$ \\
\hline
\end{tabular}

Tabel 2. Hubungan jenis epilepsi, bangkitan epilepsi, dan obat epilepsi dengan EEG

\begin{tabular}{|c|c|c|c|c|c|c|c|}
\hline & \multicolumn{5}{|c|}{ Hasil EEG } & \multirow{3}{*}{$\mathrm{p}$} & \multirow{3}{*}{ OR } \\
\hline & \multicolumn{2}{|c|}{ Normal } & \multicolumn{2}{|c|}{ Abnormal } & & & \\
\hline & $\mathrm{n}$ & $\%$ & $\mathrm{n}$ & $\%$ & & & \\
\hline \multirow{2}{*}{ Jenis epilepsi } & Umum & 55 & 54,5 & 46 & 45,5 & & \\
\hline & Parsial & 22 & 55 & 18 & 45 & 1,00 & 0,98 \\
\hline \multirow[t]{2}{*}{ Bangkitan epilepsi (jam) } & $\leq 24$ & 28 & 40.6 & 41 & 59.4 & & \\
\hline & $>24$ & 49 & 68.1 & 23 & 31.9 & 0,002 & 0,32 \\
\hline \multirow[t]{2}{*}{ Penggunaan obat anti epilepsi } & Ya & 73 & 81,1 & 17 & 18,9 & & \\
\hline & Tidak & 4 & 7,8 & 47 & 92,2 & 0,001 & 50,46 \\
\hline
\end{tabular}


Yanuar Nusca Permana dkk: Faktor-faktor yang memengaruhi gambaran elektroensefalografi interiktal anak epilepsi

Tabel 3. Hasil analisis multivariat regresi logistik

\begin{tabular}{lcccccc}
\hline & Koefisien & S.E & Wald & df & Nilai p & OR \\
\hline Penggunaan obat anti epilepsi & 3,967 & 0,611 & 42,211 & 1 & 0,000 & 52,821 \\
Bangkitan epilepsi terakhir & 1,242 & 0,506 & 6,036 & 1 & 0,014 & 3,464 \\
Konstanta & $-2,099$ & 0,415 & 25,559 & 1 & 0,000 & 0,123 \\
\hline
\end{tabular}

obat anti epilepsi sebelum pemeriksaan memberikan hasil EEG yang normal sebesar 92,2\% (Tabel 2).

\section{Pembahasan}

Subyek penelitian merupakan anak yang terdiagnosis epilepsi secara klinis yang berobat di poliklinik anak dan ruang rawat inap anak RSUP. Dr. Kariadi Semarang yang sebagian besar berjenis kelamin lakilaki dengan rentang usia 1-18 tahun. Jenis kelamin lakilaki mempunyai risiko lebih tinggi menderita epilepsi, tetapi tidak ditemukan perbedaan ras. Penelitian di Turki didapatkan 59,3\% laki-laki, sebagai faktor risiko terjadinya epilepsi. ${ }^{7}$

Sebagian besar tingkat pendidikan ayah $(58, \%)$ dan ibu $(50,4 \%)$ adalah SLTA. Sembilan puluh enam koma dua persen sumber anamnesis berasal dari ibu kandung. Tingkat pendidikan orang tua terutama ibu kandung sangat penting untuk dapat memahami kuesioner penelitian yang ditanyakan pemeriksa.

Pasien dengan jenis epilepsi umum maupun parsial tidak menunjukkan perbedaan yang bermakna mengenai hasil pemeriksaan EEG. Didapatkan 54,\% subyek dengan hasil EEG normal dan 45,4\% abnormal. Perekaman EEG rutin pada pasien epilepsi dapat tidak menunjukkan aktivitas gelombang epileptiform sekitar 50\% kasus. ${ }^{6}$ Jika EEG rutin dan EEG setelah pengurangan tidur tidak dapat menunjukkan abnormalitas EEG, dapat dilakukan long-term EEG monitoring yang dapat meningkatkan rerata deteksi dari inter iktal dan atau iktal. ${ }^{8}$ Literatur lain menyebutkan bahwa gambaran EEG abnormal akan didapatkan lebih sering jika EEG dilakukan berulang. ${ }^{9}$ Penelitian ini tidak dilakukan pengulangan pemeriksaan EEG.

Temuan EEG yang memiliki kemaknaan tinggi pada epilepsi adalah gelombang interictal epileptiform discharges (IED), yaitu gelombang epileptik yang muncul di antara bangkitan. Hasil penelitian ini menunjukkan perbedaan hasil EEG yang bermakna antara bangkitan epilepsi terakhir $\leq 24$ jam dengan bangkitan epilepsi terakhir $>24$ jam. Bangkitan epilepsi terakhir $\leq 24$ jam memberikan hasil EEG abnormal sebesar $59,4 \%$ dibandingkan bangkitan $>24$ jam yang hanya sebesar $31,9 \%$. Hasil ini sesuai dengan penelitian terdahulu yang mengumpulkan data klinis dari pasien dan saksi dari 300 orang dewasa dan anak yang mengalami kejang, dan berusaha untuk mendapatkan EEG dalam waktu 24 jam dari kejang. Hasil EEG yang didapatkan dalam waktu 24 jam lebih berguna dalam diagnosis gelombang epileptiform dibandingkan EEG $>24$ jam ( $51 \%$ vs $34 \%$ ). ${ }^{10}$

Hasil rekaman EEG dipengaruhi banyak faktor dan gangguan fungsi otak tidak selalu dapat tercermin pada rekaman EEG. Beberapa keterbatasan EEG seperti dapat mendeteksi disfungsi otak, tetapi jarang bisa menentukan penyebabnya, sensitivitas dan spesifitas relatif rendah, sering didapatkan artefak fisiologis maupun elektrik, hasil yang dipengaruhi usia, kesadaran, obat, hipoglikemi. ${ }^{11}$ Pasien yang menggunakan obat anti epilepsi sebelum pemeriksaan EEG pada penelitian ini memberikan hasil EEG abnormal sebesar $18,9 \%$, sedangkan pasien yang tidak menggunakan obat anti epilepsi sebelum pemeriksaan memberikan hasil EEG abnormal 92,2\%. Hasil ini sesuai dengan studi terdahulu yang menunjukan bahwa asam valproat menurunkan EEG synchronization pada epilepsi tipe umum. ${ }^{12}$

Variabel yang berpengaruh terhadap hasil EEG abnormal adalah penggunaan obat anti epilepsi dan bangkitan epilepsi terakhir sebelum pemeriksaan EEG. Analisis multivariat dengan regresi logistik menunjukkan probabilitas pasien epilepsi yang tidak menggunakan obat anti epilepsi dan bangkitan epilepsi terakhir kurang dari 24 jam sebelum pemeriksaan EEG memperoleh hasil EEG abnormal sebesar 95,69\%. Apabila pasien tidak mengonsumsi obat anti epilepsi dan bangkitan kejang lebih dari 24 jam sebelum pemeriksaan EEG maka probabilitas untuk mendapatkan hasil EEG abnormal sebesar $86,65 \%$. Jika pasien mengonsumsi obat anti epilepsi 
dan bangkitan kejang terakhir sebelum pemeriksaan EEG kurang dari 24 jam maka probabilitas untuk memperoleh hasil EEG abnormal sebesar 29,79\%. Sementara pasien epilepsi yang mengonsumsi obat anti epilepsi dan bangkitan kejang lebih dari 24 jam sebelum pemeriksaan EEG probabilitasnya hanya 10,92\% hasil EEG abnormal.

Keterbatasan penelitian ini adalah tidak memperhitungkan jenis obat anti epilepsi, frekuensi kejang dan lama menderita epilepsi sebelum pemeriksaan EEG serta kesulitan dalam melakukan pemeriksaan EEG rutin sesegera mungkin setelah penderita epilepsi anak terdiagnosis.

\section{Kesimpulan}

Bangkitan epilepsi terakhir dan penggunaan obat anti epilepsi merupakan faktor yang mempengaruhi gambaran EEG inter iktal anak yang menderita epilepsi. Jenis epilepsi tidak memengaruhi gambaran EEG inter iktal anak yang menderita epilepsi. Disarankan untuk pemeriksaan EEG yang sebaiknya segera dilakukan dalam 24 jam dikarenakan lebih berguna dalam mendiagnosis gelombang epileptiform abnormal dibandingkan EEG yang dilakukan >24 jam. Penggunaan obat anti epilepsi meskipun memengaruhi gambaran EEG, namun untuk menghentikan obat anti epilepsi saat pemeriksaan EEG tetap mempertimbangkan kondisi klinis.

\section{Daftar pustaka}

1. Wishwadewa WN, Mangunatmadja I, Said M, Firmansyah A, Soedjatmiko, Tridjaja B. Kualitas hidup anak epilepsi dan faktor-faktor yang mempengaruhi di Departemen Ilmu Kesehatan Anak FKUI/RSCM Jakarta. Sari Pediatri 2008; 10:272-9.
2. Adelow C, Andell E, Amark P, Andersson T, Hellebro E,Ahlbom A, Tomson T. Newly diagnosed single unprovoked seizures and epilepsi in Stockholm, Sweden: first report from the Stockholm Incidence. Registry of Epilepsi (SIRE). Epilepsia 2009;50:1094-101.

3. Kelompok Studi Epilepsi. Dalam: Kusumastuti, Kustiowati E, Gunadharma S, editor. Pedoman tata laksana epilepsi. Edisi Ke-3. Jakarta: Perdossi; 2006.h.1-43.

4. Uldall P, Alving J, Hansen LK, Kibaek M, Buchholt J. The misdiagnosis of epilepsy in children admitted to a tertiary epilepsy centre with paroxysmal events. Arch Dis Child 2006;91:219-21.

5. Major P, Thiele EA. Seizure in children: laboratory, diagnosis, and management. Pediatr Rev 2007;28:405-14.

6. DeRoos ST, Chillag KL, Keeler M, Gilbert DL. Effect of sleep deprivation on the pediatric electroencephalography.Pediatrics. 2009;123:703-8.

7. Aydin A, Ergor A, Ergor G, Dirik E. The prevalence of epilepsy amongst school children in Izmir. Turkey Seizure 2002;11:392-6.

8. Flink R, B Pedersen, A B Guekht, K Malmgren, R Michelucci, $\mathrm{B}$ neville, dkk. Guidelines for the use of EEG methodology in the diagnosis of epilepsy. International League Against Epilepsy: Commission report. Commission on European affairs: Subcommission on European guidelines. Acta Neurol Scand 2002;106:1-7.

9. Salinsky M, Kanter R, Dasheiff RM. Effectiveness of Multiple EEGs in Supporting the Diagnosis of Epilepsy: An Operational Curve. Epilepsia 1987;28:331-4.

10. King MA, Newton MR, Jackson GD, Fitt GJ, Mitchell LA, Silvapulle MJ, dkk. Epileptology of the first-seizure presentation: a clinical, electroencephalographic, and magnetic resonance imaging study of 300 consecutive patients. Lancet 1998;28:352:1007-11.

11. Bintoro AC. Pemeriksaan EEG untuk diagnosis dan monitoring pada kelainan neurologi.Med Hosp 2012;1:64-70.

12. Clemens B. Valproate decreases EEG synchronization in a use-dependent manner in idiopathic generalized epilepsy. Seizure 2008;17:224-23. 